\title{
Fielding of the On-Axis Diagnostic Package at $\mathrm{Z}$.
}

M. J. Hurst, T. J. Nash, M. Derzon, J.W. Kellogg, J. Torres, J. McGurn, J. Seaman, Sandia National Laboratories, Albuquerque, NM

\author{
D. Jobe, S. E. Lazier \\ K-tech Corp., Albuquerque, NM
}



We have developed a comprehensive diagnostic package for observing z-pinch radiation along the pinch axis on the $\mathrm{Z}$ accelerator. The instrumentation, which was fielded on the axial package, are $\mathrm{x}$-ray diagnostics requiring direct lines of sight to the target. The diagnostics require vacuum access to the center of the accelerator. The environment is a hostile one, where we must deal with an intense, energetic photon flux (>100 keV), EMP, debris (e.g. bullets or shrapnel), and mechanical shock in order for the diagnostics to survive. In addition, practical constraints require the package be refurbished and utilized on a once a day shot schedule. In spite of this harsh environment, we have successfully fielded the diagnostic package with a high survivability of the data and the instruments. In this paper, we describe the environment and issues related to the re-entrant diagnostic package's implementation and maintenance.

\section{INTRODUCTION}

The $\mathrm{Z}$ accelerator ${ }^{1}$ is capable of producing $>1.8 \mathrm{MJ}$ of soft $\mathrm{x}$-rays in $<10 \mathrm{~ns}$, with nearly $20 \mathrm{MA}$ flowing through the diode. As byproducts to its operation there is a EMP field, a high-energy photon field (bremsstrahlung) ${ }^{2}$, shock and debris. The environment for this is illustrated in Fig. 1a, where the machine configuration is shown. There is a large Marx bank (the capacitor banks where the energy is stored), and a series of pulse forming and 
power transmission lines leading to the center of the machine. It is the center of the machine, where the z-pinch target to be diagnosed is placed and it is the region around this target, within a 2 inches radius of the machine center, that is of interest for these experiments. This region is shown in Fig. $1 \mathrm{~b}$, the anode and cathode as well as a simplecentral target are illustrated in the figure.

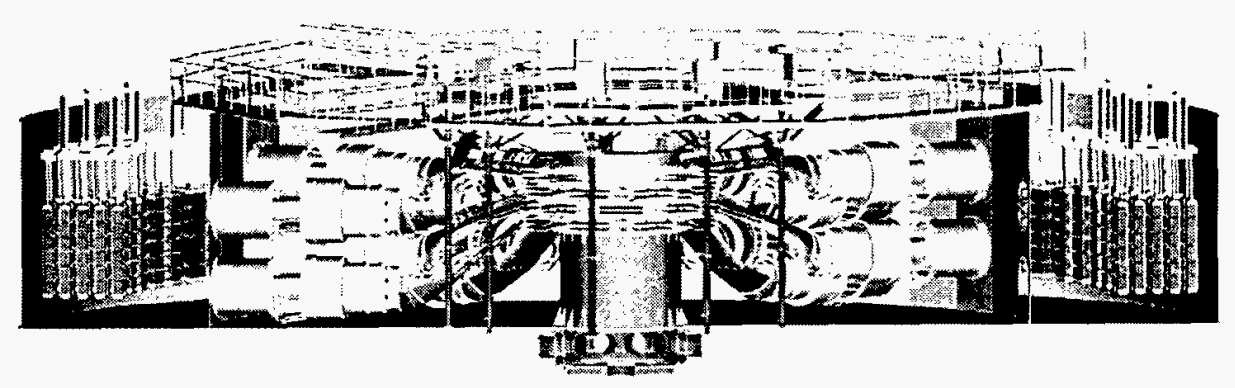

(a)

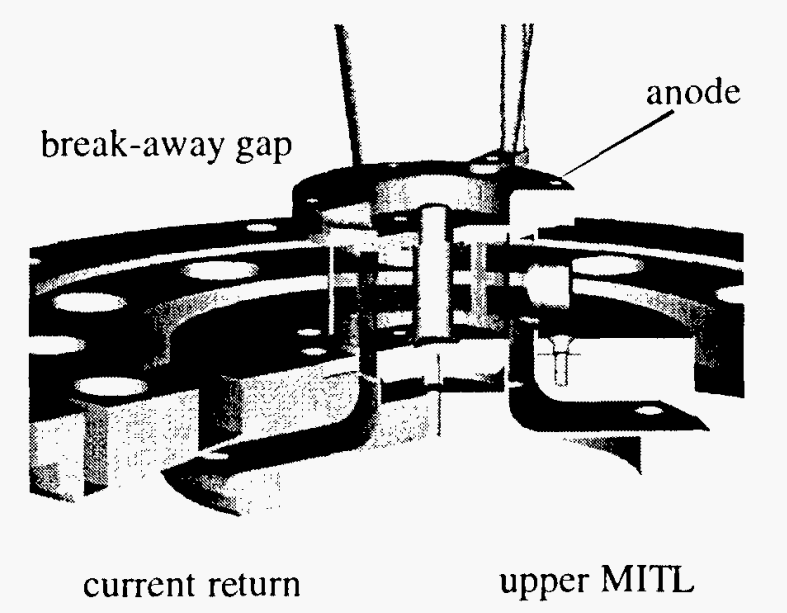

\section{Diode Hardware at $12^{\circ}$}

(b)

Fig.1a) $\mathrm{Z}$ machine side view.2) Diode region holding on-axis annular target.

The package has allowed us to study pinch physics that has not been accessible in the past. An example of this is shown in Fig.2. The figure shows a framing camera image (2ns wide) of the $\mathrm{x}$-ray emission generated as an outer tungsten wire array is imploded 


\section{DISCLAIMER}

This report was prepared as an account of work sponsored by an agency of the United States Government. Neither the United States Government nor any agency thereof, nor any of their employees, makes any warranty, express or implied, or assumes any legal liability or responsibility for the accuracy, completeness, or usefulness of any information, apparatus, product, or process disclosed, or represents that its use would not infringe privately owned rights. Reference herein to any specific commercial product, process, or service by trade name, trademark, manufacturer, or otherwise does not necessarily constitute or imply its endorsement, recommendation, or favoring by the United States Government or any agency thereof. The views and opinions of authors expressed herein do not necessarily state or reflect those of the United States Government or any agency thereof. 
onto a gold annulus. The nine-fold symmetry pattern observed is due to the nine diagnostic slots used to view the pinch from the side. ${ }^{3}$



Fig.2. Effect of pinch asymmetry due to side-viewing diagnostic slots.

The diagnostic package, see Fig. 3, holds many instruments and a listing of these is provided in Table 1. They enable measurement of target hydrodynamic phenomenon, temperature, and symmetry.

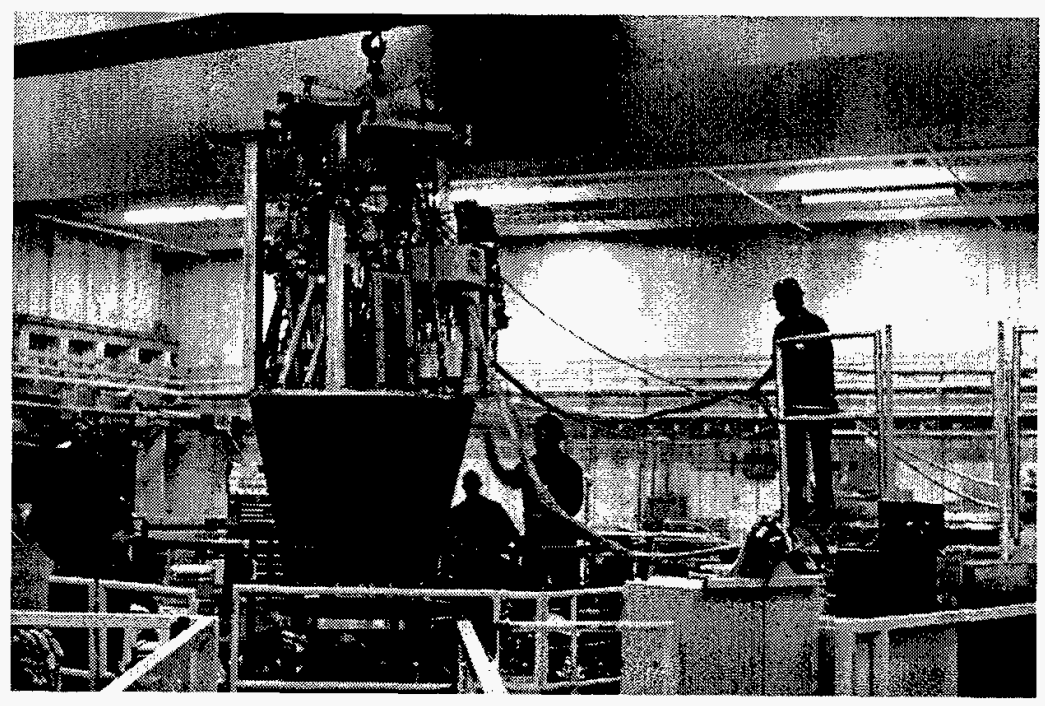

Fig. 3. The $\mathrm{Z}$ diagnostic package as it gets lowered into the center of the $\mathrm{Z}$ machine. 
Table 1. Diagnostics fielded in the on-axis package, data obtained, typical angles with respect to the axis and maintenance required between shots.

\begin{tabular}{|c|c|c|c|}
\hline Instrument & Viewing Angle & Data Obtained & Maintenance \\
\hline EST & 6 degree & Energy ( 2 band passes) time space & $\begin{array}{l}\text { Replace filters and imaging slits, } \\
\text { realign }\end{array}$ \\
\hline OAT & 0 degree & Shodowgraphy optical attenuation & Replace debris shiclds, realign \\
\hline Pin Hole 2/3 Mag & 6 degree & Gated 2d imaging & $\begin{array}{l}\text { Replace filters, inspect pinholes debris } \\
\text { shields, realign }\end{array}$ \\
\hline Pin Hole 1/3 Mag & 6 degree & Gated $2 \mathrm{~d}$ imaging & $\begin{array}{l}\text { Replace filters, inspect pinholes debris } \\
\text { shields, realign }\end{array}$ \\
\hline XRD & 9 degree & Bandpass filtered spectrum & Inspect filters and replace, realign \\
\hline TRXSPEC & 9 degree & Time resolved spectroscopy & Inspect imaging slit \\
\hline TIXSPEC & 9 degree & $1 \mathrm{~d}$ imaging spectrometer & Inspect imaging slit \\
\hline Bolometer & 9 degree & Energy & Inspect detector for damage \& realign \\
\hline Calorimeter & 9 degree & Energy & Remove and inspect detector, realign \\
\hline Angar Spectrometer & 0 and 6 degree & Time in space resolved spectra & $\begin{array}{l}\text { Remove instrument realign in light lab. } \\
\text { Reinstall and align to the accelerator }\end{array}$ \\
\hline $\begin{array}{l}\text { Long Focal Length } \\
\text { Microscope }\end{array}$ & 9 degree & Picture of target before it is shot & Realign to target \\
\hline Illumination Laser & 9 degree & $\begin{array}{l}\text { Target illumination for remote } \\
\text { viewing }\end{array}$ & Realign to target \\
\hline
\end{tabular}

\section{THE ENVIRONMENT AT Z (DEBRIS, BREMSSTRAHLUNG, AND SHOCK)}

Of the many hazards posed by the $\mathrm{Z}$ accelerator the most difficult to design for was the shrapnel plume produced on the Z-axis when the accelerator fires. Some of the shrapnel 
produced has had the equivalent size of 45 caliber slugs with velocities high enough to produce 1/4" deep gouges in the stainless steel vacuum chamber walls.

Two design approaches were considered to mitigate the shrapnel problem. The first was to use distance to reduce the likely hood of damage to the instrumentation and the second was to use sacrificial aperture plates to stop the shrapnel threat with a fast closing valve at the detector as resort protection. All of the line of sight tubes were constructed out of heavy walled stainless steel tubing to provide protection from penetration from shrapnel and rigidity against the shock load produced by the accelerator. Two x-ray pinholeimaging cameras with $1 / 3$ and 2/3-target magnification were fielded with the on-axis package. Between the target and the micro-channel plate detector several debris aperture plates were used. A cylindrical top cover approximately 36 inches tall was placed over the target to provide the first level of protection from shrapnel. The top plate of this shield was constructed out of $1 / 2$ " thick copper having an array of _" diameter viewing holes for the lines of sight of the on-axis instrumentation. This plate had to be replaced periodically due to the deformation of the plate caused by the force of shrapnel.

A second _" thick stainless steel shrapnel shield was mounted to the bottom side of the axial package with mounting points to install 1" diameter aperture plates for each line of sight. This shield was required to protect the underneath of the axial package from debris damage. Four additional barriers were used for protection inside the instrument. A _" thick shrapnel shield was located in front of the pinhole aperture plate with an array of 
24-1/8" diameter holes, which coincided, with the lines of sight of the pinholes. The 0.010 " thick titanium pinhole plate was the next layer of protection.

The aperture plate with 80 micron diameter pinholes was sandwiched between a _." thick stainless steel holding plate with x-ray filters located behind the pinholes. All of these items were consumables, meaning they required frequent replacement between shots. A final large aperture fast valve was located at the detector as the last line of defense for protection of the 12-strip detector. All of theses preventative measures worked well for shrapnel protection during the initial 10 shot series. The worst damage to this instrument was when a large shrapnel piece was captured by the first debris shield inside the camcra resulting in a _" deep dimple in the _" thick stainless steel plate.

Along with the large shrapnel pieces fine vaporized metal was also generated during each shot. The metal vapor was deposited all the way through the system up to the pinhole aperture plate. This film would occasionally obscure the pinholes requiring replacement of the aperture plate. No shrapnel damage occurred beyond the pinhole aperture plate during the fielding of these instruments.

Mechanical shock was the next most difficult problem to deal with. The $\mathrm{Z}$ accelerator generates a severe shock wave during each shot. The difficulty was to design a mounting system which would allow alignment of the instrumentation to the target with angular adjustment but still stay rigid enough to prevent damage to the instrument during the shot. Estimates of the shock wave forces were in the 100 to $200 \mathrm{G}$ range, however, no 
measurements had been made at the time of the on-axis instrumentation design. A gimbaled design used during the first fielding provided to be too weak resulting in bending and breakage of the frame. The line of sight tubes were supported by three push type clamps, which had pivoting V blocks to support the line of sight tube. During the experiments these $3 / 8$ " diameter threaded clamps were repeatedly bent during the machine shot which had to be replaced after several shots. A new gimbal design with a thicker frame solved the breakage problem.

Electromagnetic pulsed noise was another byproduct of the $\mathrm{Z}$ accelerator. To minimize this problem, the data collection equipment and electronic support equipment were placed inside of shielded enclosures. The emitted electromagnetic spectrum and the intensity emitted by the $\mathrm{Z}$ accelerator has not been quantified, however, past experience has shown that double shielding of the signal cables and placement of the electronics and data recording equipment inside faraday cage enclosures is a necessity. All signal cables were also keep as short as possible by locating the data collection enclosure as close to the diagnostic package as possible to reduce signal degradation.

Bremsstrahlung radiation was another byproduct of the accelerator. This effect could be seen as a slight clouding of the film used in the framing cameras for data collection during each shot. Tantalum was used as the aperture plate material to try to minimize this effect. Individual detectors do and will require additional shielding as necessitated by their sensitivity to this effect. 


\section{SUMMARY}

A diagnostic package has been built and operated on the $\mathrm{Z}$ facility to obtain comprehensive information about z-pinch implosion physics. The instrumentation, although difficult to field, has enabled the acquisition of new and important information about z-pinches and high energy density materials.

\section{ACKNOWLEDGEMENTS}

This work supported by the U.S. Department of Energy under Contract DE-AC0494AL85000. Sandia is a multi-program laboratory operated by Sandia Corporation, a Lockheed-Martin Company, for the United States Department of Energy.

\footnotetext{
1 Spielman R.B., C. Deeney, G.A. Chandler et al. (1997). "PBFA Z: a 60 TW/5MJ Z-pinch driver." In: "Dense Z-pinches," AIP Conference Proceedings, v. 409, p. 101.

${ }^{2}$ Rochau, G.A., M.S. Derzon, D. Fehl, R. Mock, C. Ruiz, M.A. Sweeney, K. Struve,S. Lazier, G. Cooper, Bull. of the APS_DPP (1997), 'Bremsstrahlung Measurements at $Z$ '

${ }^{3}$ Nash, T. J., M.S. Derzon, G. Allshouse, C. Deeney, D. Jobe, J. Seaman, T. Gilliland, and J. McGurn, Rev. Sci. Instr., 68, part 2, 1083(1997)

Derzon, M.S., et al, Bull. of the APS DPP(1997), 'Dynamic Hohlraum results from Saturn and ' $Z$ ' experiments'
} 


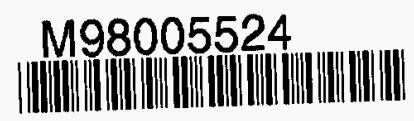

Report Number (14) $\frac{\operatorname{SAND}--98-1.282 \mathrm{C}}{\text { CONF }-980605--}$

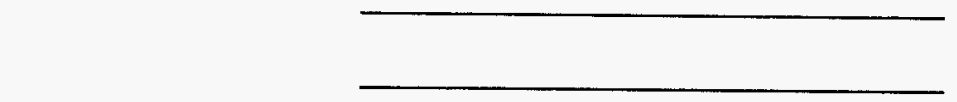

Publ. Date (11) 199806

Sponsor Code (18) DOE IDP , XF

UC Category (19) UC-700, DOE/ER 